\title{
Internet-Based Commons of Intellectual Resources: An Exploration of their Variety
}

\author{
Paul B. de Laat \\ Faculty of Philosophy, University of Groningen, \\ The Netherlands, P.B.de.Laat@rug.nl
}

\begin{abstract}
During the two last decades, speeded up by the development of the Internet, several types of commons have been opened up for intellectual resources. In this article their variety is being explored as to the kind of resources and the type of regulation involved. The open source software movement initiated the phenomenon, by creating a copyrightbased commons of source code that can be labelled 'dynamic'; allowing both use and modification of resources. Additionally, such a commons may be either protected from appropriation (by 'copyleft' licensing), or unprotected. Around the year 2000, this approach was generalized by the Creative Commons initiative. In the process they added a 'static' commons, in which only use of resources is allowed. This mould was applied to the sciences and the humanities in particular, and various Open Access initiatives unfolded. A final aspect of copyright-based commons is the distinction between active and passive commons: while the latter is only a site for obtaining resources, the former is also a site for production of new resources by communities of volunteers ('peer production'). Finally, several patent commons are discussed, which mainly aim at preventing patents blocking the further development of science. Throughout, attention is drawn to interrelationships between the various commons.
\end{abstract}

Keywords: commons, copyright, licenses, open source software, patent

\section{Introduction}

Both natural and intellectual resources can be held in a commons. That is, according to the common legal definition, everybody is privileged to use them, and nobody has the right to exclude others from use. During the last decades, the commons phenomenon has increasingly attracted attention. This article will focus in particular upon commons of intellectual resources, and their further expansion as facilitated by

Please use the following format when citing this chapter:

de Laat, P., 2006, in IFIP International Federation for Information Processing, Volume 223, Social Informatics: An Information Society for All? In Remembrance of Rob Kling, eds. Berleur, J., Numinen, M. I., Impagliazzo, J., (Boston: Springer), pp. 171-183. 
the Internet. I intend to show that talking about the Internet-based commons in general is not very helpful. Instead, it is more useful to distinguish between several commons that differ as to the kind of resources and the amount of regulation involved. Throughout it will be argued, that the open source software movement has paved the way, and all subsequent - broader - developments have been modelled upon it.

\section{Open Source Software}

The term 'intellectual products' may refer to a whole range of creative activities of the human mind: natural and social sciences, technology, the humanities, and art (literature, paintings, photographs, film, music). Expressions of creativity in these domains may enjoy copyright protection (and as a matter of fact, nowadays this protection obtains automatically upon production). Such copyrighted products, by definition, do not constitute a commons accessible for all. Instead, any use or reuse depends on permission of the copyright holders. In the last decades, a remarkable development has taken place. While many producers wanted a more active circulation for the intellectual resources that they created, they invented (legal) mechanisms to allow use and sometimes even modification without previous permission being needed.

It was the movement to liberate software in particular that started this development. In the 1980 s already, in pre-Internet times, volunteer software developers were used to exchanging their creations amongst each other, hoping for useful comments, detection of bugs, patches for them, and new features. In this ongoing process, the software involved would become ever better and ever more reliable. This cooperation among 'hackers' (as they call themselves) depended critically upon exchanging the source code of programs as written in one of the available computer languages, as only then a program can be understood and analyzed properly. As soon as source code has been compiled into object code, an unintelligible string of $0 \mathrm{~s}$ and $1 \mathrm{~s}$ is the result.

On what terms these programs were made available? Hackers could have opted for releasing their products in the public domain, as for example was the standard procedure for software from US government agencies. This commons, however, was not acceptable to most of them, because they wanted to impose at least some regulations upon fellow hackers. A 'regulated commons' was their preferred choice. One concern, for example, was that the original authorship of pieces of code should remain visible during the ongoing process of source code modification. The approach chosen to actually prescribe regulations was to claim copyright, and on this base write so-called copyright licenses. Such licenses typically allow free use and modification of code, as well as (re)distribution of (modified) source code (cf. the open source definition in OSI 1997-2005, for what around the year 2000 came to be christened 'open source licenses'). These regulations, therefore, draw their juridical strength from the combination of copyright law and contract law. 
From the very beginning these licenses fell into two separate categories, creating either a commons protected from appropriation, or an unprotected one. Let me explain. One of the oldest licenses is the General Public License (GPL) as formulated by Richard Stallman in the early 1980s, also colloquially referred to as 'copyleft' [FSF/GNU 1989/1991]. It accompanied software packages like his GNU C compiler and GNU Emacs editor. As a more famous example of a later date, the kernel of the Linux operating system carries GPL-terms. The license allows free use, modification and (re-)distribution of code, as any other open source license. In addition, however, any distribution of modified GPL-ed code must carry the GPL again, no other terms of distribution are allowed. More broadly, any program that includes GPL-ed fragments ('a work based on the program') may only be published under GPL-conditions. In this way, an endless cycle governed by the GPL ensues. The license does not, as it is sometimes maintained, preclude composing a modified version in object code and selling it on the market for money. However, any buyer may request access to the program in source code, with a GPL attached. This obligatory offer creates the possibility of retrieving the source code at all times. No branch of the project is permitted to gravitate outside the public view forever. Effectively, this commons is protected from private appropriation. In a metaphorical sense, the GPL creates a dam around the lake of source code, preventing irreversible leakage towards lower (commercial) regions. Such a dam is important, while it addresses one of the central problems of a commons: how to maintain the resources in good condition ('provisioning problem')?

On the other hand we find the Berkeley Software Distribution license, dating from the late 1980s, which accompanied the various free Unix-releases. Also the well-known Apache webserver software has evolved under its terms. This license, and others very similar to it, provide the same freedoms as any other open source license (of use, modification and redistribution), while adding no restrictions whatsoever upon the process. Literally everything is allowed, if only the original copyright notices are retained all along (which, by the way, the GPL also requires) [BSD 1998]. So here we have a commons which is not protected from 'appropriation': anyone may modify BSD licensed code and sell it in closed form, without being obliged to disclose the source code upon request. As a consequence, a path may branch off ('fork') from the public project and be developed further outside the commons. In terms of the metaphor from above: this lake is not protected by a dam, and the water is free to take its 'natural' course.

In actual fact, some 20 to 30 other open source licenses are in use, as drafted from the 1980s onwards by volunteers, not-for-profit organizations and companies. However, apart from hardly being used, these do not introduce a substantially new type of license. Although minor details of implementation are different, they can be classified as either GPL-like or BSD-like licenses [cf. De Laat 2005]. Protective and non-protective types of open source licenses are the two main classes to be distinguished.

This movement for opening up software is not just a marginal phenomenon. After a slow start in the 1980 s, the pace of the movement has been accelerating sharply in the 1990 s, mainly because the Internet allows instant reproducibility. The 
biggest open source platform of today, sourceforge, claims to host over 100,000 projects, populated by over a million participants. Available statistics indicate that the protected commons is the preferred option ( $79 \%$ of packages carry a GPL-like license); the unprotected commons is much smaller (14\% of licenses are BSD-like) (figures deduced from sourceforge statistics, as retrieved from http://sourceforge.net/softwaremap/trove_list.php?form_cat=13; cf. De Laat 2005).

As one of the first moves outside the domain of software proper the so-called GNU Free Documentation License (GFDL) deserves to be mentioned here [FSF/GNU 2002]. This license, drafted by the FSF in order to accompany written manuals for GPL-ed software, is similar to the GPL in allowing the free use, modification and redistribution of the texts involved, whether commercially or noncommercially. Any redistribution, furthermore, is to carry the same GFDL terms. So, essentially, this is the GPL for source code transformed to apply to text. Notice that the whole problematic of source code versus object code is absent here. While manuals are simply text, in no need to be compiled, the elaborate provisions as formulated in the GPL to guarantee the return of (updated) source code to the commons are no longer necessary. All modified manuals as published are automatically intelligible. Only a faint echo applies: according to the GFDL, any copy or modification must be 'transparent', not 'opaque': the text must be in a format that allows easy machine manipulation and modification by users.

\section{Creative Commons Initiative}

The open source movement captured the imagination of many people working outside software. In the sciences, the humanities and art the very same ideas of 'freeing culture' and 'permanent re-use of culture' were taken up. Especially Stallman's ideas about a commons protected against unwanted appropriation acquired many followers. Along the lines of copyleft many academics and artists took to writing down licenses for their specific outputs. Around the turn of the century a series of licenses became drafted: for text generally (Open Content and Open Publication Licenses), for art in general (e.g., the Free Art License), and for media works (e.g., the Design Science License) and music (e.g., the Open Audio License, the Green Open Music License) in particular [cf. Liang 2004].

A more comprehensive approach, however, only came about as a result of the efforts of Creative Commons, a non-profit corporation based at Stanford University. In 2002 they formulated their approach to choosing an appropriate license (information below drawn from http://creativecommons.org). For a license that allows one's work to be freely copied, distributed, displayed and performed, four conditions have to be specified: i) Attribution: whether one requires to be properly credited as the author, or not; ii) Type of use: whether one allows use for noncommercial purposes only, or for any purpose; iii) Derivative works: whether one allows distribution of derivative works, or not; and iv) Type of license: whether derivative works should carry the same license as the original, or any license is allowed. 
After the introduction of these licenses nearly every user turned out to require proper attribution. Therefore Creative Commons decided to simplify their approach and declare attribution the default option. As a result, 6 types of license remain (not 8 , while the license condition makes no sense if derivations are not allowed): 1) For non-commercial purposes only; no derivative works; 2) For non-commercial purposes only; derivative works allowed, if carrying the same license; 3) For noncommercial purposes only; derivative works allowed with any license; 4) For all purposes; no derivative works; 5) For all purposes; derivative works allowed, if carrying the same license; 6) For all purposes: derivative works allowed with any license. In Table 1 these 6 licenses are listed systematically, together with the abbreviations as used by the Creative Commons corporation.

Table 1. Classification of creative commons licenses and comparison with open source licenses

\section{For non-commercial purposes only}

(1) no derivative works ('by-nc-nd')

(2) derivative works allowed: with same license ('by-nc-sa')

(3) derivative works allowed: with any license ('by-nc')

\section{For all purposes}

(4) no derivative works ('by-nd')

(5) derivative works allowed: with same license ('by-sa')

(6) derivative works allowed: with any license ('by')

(5) corresponds to GPL-like licenses for software

(6) corresponds to BSD-like licenses for software

This taxonomy is an important step forward for several reasons. For one thing, it is not geared to a specific type of content, but may presumably cover all content. Any text, photograph, film, music, in fact, anything copyrightable can henceforth be licensed properly. Specific licenses as drafted in the past are no longer needed. One exception applies however: because of the distinction between source code and object code, the specific licenses for software - and software manuals - as discussed above remain the preferred choice.

In fact it is useful to compare the commons as created by this corporation, with the commons as opened up by the open source movement. The systems correspond to each other closely. No wonder, as the people behind the creative commons approach draw their inspiration from precisely that movement. The source code commons as protected by the GPL corresponds to license 5, while the unprotected commons carrying BSD-like licenses corresponds to license 6 (as specified above; see Table 1). From Table 1 it can clearly be seen that, on the one hand, the creative commons approach has defined a new type of commons, consisting of content that may be used freely in verbatim form, but not modified or transformed in any way. Such a restrictive commons does not, of course, allow experimentation and innovation too close to the original expression. Therefore I will refer to it as a 'static' commons. For hackers, this is a non-option while the whole point of open source is to create an ongoing cycle of improvements. Nevertheless, such a static 
commons may be a useful addition, while sometimes creators of content just want their work to be known.

On the other hand, the Stanford approach has introduced a distinction that has always been absent from the mainstream of the open source movement: the distinction between commercial and non-commercial uses of content. Hackers have always been anxious to include participants from all quarters, in order to maximize participation in innovation. Nevertheless, this distinction may appeal to creators of content that want to stay aloof from commercial exploitation.

I shall now proceed to discuss some initiatives that unfolded under this creative commons umbrella, in order to show how the idea of opening up commons has taken root outside the domain of software. These examples are all drawn from the sciences and the humanities. Concerning art, I have not been able to detect significant commons filled with artistic resources. In line with the analysis above, I distinguish between a static commons, a dynamic commons (either protected or unprotected), and the public domain (which is dynamic per definition). All along, commercial and non-commercial purposes will be considered together.

\section{Open Access}

The 'Open Access Initiative' focuses upon the sciences and the humanities only (the following is based on Suber 2004/5). It strives for open access to this literature through the Internet, which has two main dimensions. On the one hand, access should be free of charge. On the other, access should not be encumbered by the usual copyright restrictions, but allow the free use of accessed texts. Meetings in Berlin, Bethesda and Budapest of interested participants have produced statements of purpose and intent. The movement may be analyzed as the outcome of conflicting trends [cf. PLOS 2003]. On the one hand, public interest in scientific information seems to be growing, which need could be accommodated by the development of the Internet, allowing easy and instant access. This promise, however, is thwarted by rising prices and 'bundling' of journals that publishers impose upon research libraries. Open Access tries to save this original promise of the Internet.

They propose to 'free' the scientific literature by two main vehicles. First, the initiative pleads for the establishment of open access journals; i.e. fully peer reviewed journals that publish on the Internet without access fee. The cost of publication is shifted from users to producers of content (or their employers like the university) or to funding institutions. Such open access journals may be newly established, or the outcome of conversion of existing subscription-based journals. Secondly, open access archives (or repositories) are being proposed, whether centralized or decentralized, equipped with all available search facilities. Operating without peer review, they are intended to be, one might say, the free abode for all scientific output (beside commercial textbooks) in a specific field or setting. For one thing, they are to be the outlet for dissertations, research findings, course materials, data files, and the like. For another, the content of all journals is to be deposited here, both the classically run restricted-access journals and open access journals. 
What kinds of commons are opened up by Open Access? They are precisely the regulated ones as proposed by the Creative Commons corporation. The creative commons licenses are explicitly recommended as legal vehicles. Additionally, the public domain is mentioned as a possible option. The Open Access Initiative may be said to embrace the creative commons framework. Nevertheless, ambiguities remain in this respect. Adherents produce confusing statements about the amount of freedom to be allowed. The Budapest Initiative (2002) defined 'open access' as 'free availability on the Internet, permitting any users to read, download, copy, distribute, print, search, or link to the full texts of these articles (...)'. If I interpret this definition as 'allowing at least so many freedoms', it refers to all creative commons licenses (the whole of Table 1). Both the Bethesda Statement (April 2003) and the Berlin Declaration (October 2003), however, proposed to grant a broader license "to copy, use, distribute, transmit and display the work publicly and to make and distribute derivative works (...)' [italics added; PdL]. To my view, this clearly represents a 'by' license (license 6, Table 1), allowing anything subject to proper attribution. It seems safe to conclude that a considerable amount of freedom of opinion (or confusion?) is present in the movement. In order to accommodate this variety, in Table 2 Open Access is represented as covering the whole commons spectrum, from a static commons up to the public domain.

Table 2. Various open content initiatives classified according to the domain to which they apply and the type of copyright-based commons created

\begin{tabular}{|c|c|c|c|c|}
\hline $\begin{array}{l}\text { Copyright- } \\
\text { based text } \\
\text { commons } \rightarrow \\
\text { Domain } \downarrow\end{array}$ & $\begin{array}{l}\text { Static } \\
\text { (cc-licenses } 1 \\
\& 4)\end{array}$ & $\begin{array}{l}\text { Dynamic: } \\
\text { Protected } \\
\text { (GPL-like, } \\
\text { copyleft) } \\
\text { (cc-licenses } 2 \text { \& } \\
\text { 5) }\end{array}$ & $\begin{array}{l}\text { Dynamic: } \\
\text { Unprotected } \\
\text { (BSD-like) } \\
\text { (cc-licenses } 3 \\
\text { \& 6) }\end{array}$ & $\begin{array}{l}\text { Dynamic: } \\
\text { Public } \\
\text { domain }\end{array}$ \\
\hline Software & & $\begin{array}{l}\text { GNU C compiler } \\
\text { Linux } \\
\text { Mozilla/Firefox }\end{array}$ & $\begin{array}{l}\text { BSD (Unix) } \\
\text { Apache }\end{array}$ & \\
\hline $\begin{array}{l}\text { Software } \\
\text { manuals }\end{array}$ & & FSF-manuals & & \\
\hline \multirow[t]{2}{*}{$\begin{array}{l}\text { Sciences and } \\
\text { humanities }\end{array}$} & Open Access & Open Access & $\begin{array}{l}\text { Open Access } \\
\text { PLOS } \\
\text { BioMed }\end{array}$ & Open Access \\
\hline & & $\begin{array}{l}\text { HapMap } \\
\text { (initially) }\end{array}$ & & $\begin{array}{l}\text { HapMap } \\
\text { (ultimately) }\end{array}$ \\
\hline Encyclopedias & & Wikipedia & & \\
\hline
\end{tabular}

\footnotetext{
Carrying the Mozilla Public License that provides less protection than the GPL.
}

Italicized initiatives involved in 'peer production' 
Noticeably, not any of these statements makes a point of protecting the commons, a point the open source movement has forcefully called our attention to. Nobody seems particularly worried that the commons may be drained by commercial interests. A reason might be that modified software with a commercial license becomes inscrutable (while in object code), while modified text remains comprehensible. So any modified text taken outside the commons may easily be recovered - not literally of course (copyright preventing), but after rephrasing.

While this movement has been active for several years now, a sizeable number of journals is currently operating along these lines: about 2000 (cf. 'Directory of open access journals', located at http://www.doaj.org). What kind of commons is being instituted by these journals? A (very) rough perusal of editorial licensing policies suggests that most retain copyright, allowing free copying and distribution but no derivative works (sometimes non-commercially only). That is, they effectively implement creative commons licenses 1 and 4 (no derivative works).

Exceptions to this rule, by allowing derivative works, are two well-known initiatives: the non-profit Public Library of Science (PLOS) and the for-profit BioMed Central. PLOS is an organization of scientists and physicians that was launched in 2000 in order to turn their specialist literature into a public resource (all information below retrieved from http://www.plos.org). While their attempts to let existing journals open up their contents to 'free access' in webarchives were hardly successful, they decided to launch their own peer-reviewed journals instead. The first 'PLOS journal', PLOS Biology, appeared in 2003, followed by several others afterwards. For our discussion it is interesting to observe, that PLOS chose the commons with the broadest amount of freedom (apart from the public domain): license 6 ('by' license, see Table 1; Table 2). They did this consciously, while they feel that any risk of plagiarism or misattribution is more than outweighed by potential 'creative uses' of published content. In this vein, they explicitly alert content users to the possibilities of 'reuse and transformation', and 'translation and republication', as long as proper attribution is not neglected (see http://www.plos.org/creative_uses/). The second exception to the rule is BioMed Central (cf. http://www.biomedcentral.com). This for-profit organization focuses upon biomedical research and also issues open access journals, numbering about 130 now. Their copyright policies are similar to PLOS: authors retain copyright, but allow downloading for free as long as users consent to an Attribution License (license 6, Table 1; Table 2).

Before concluding this section on the sciences and the humanities it is illustrative to note a volunteer initiative at its edges: the Wikipedia project (information below retrieved starting from en.wikipedia.org/wiki/Main_Page). It aims at producing a free online encyclopedia. Just like in open source communities, users are invited to turn into producers. Actually, anyone is invited to join and modify existing entries without restrictions. At this time of writing, it boasts of over a million articles (of which $70 \%$ in English) and over half a million participants. What kind of commons is involved here? They have chosen the GFDL as discussed above. So here we find a protected commons, where modifications are encouraged but only to be redistributed under the same GFDL terms (Table 2). Why 
this preference for protection? While the Wikipedia itself does not, oddly enough, provide any rationale, I will venture my own explanation. Their output is not software, but pure text or images. Such an output does not need protection per se as explained above. I would argue that another explanation imposes itself: we are dealing here with volunteers, not paid professionals. These would not like to see their creations usurped by commercial producers of encyclopedias, that for example could set up a commercial website featuring a selection of reliable (and possibly upgraded) entries from the Wikipedia, omitting the (as yet) lesser developed sections. Customers would be made to pay for (supposed) reliability and consistency.

\section{Active Commons}

The foregoing exhausts the new kinds of copyright-based commons that are currently being opened up. One more element, however, needs mentioning. Some of these are promoted with more in mind than just enabling public access. To their proponents, the commons is not only a place for downloading resources, but also for collectively creating new resources from them. An alternative model of knowledge development as carried out by volunteers is the ultimate goal. In Benkler's words: 'peer production of knowledge' that does not rely on markets or managerial hierarchy. Such a commons will be denoted as an 'active' commons (and corresponding instances in Table 2 italicized).

The prototype of this ambition is, again, the open source movement. Source code is being made freely available for all, nowadays mainly on platforms like sourceforge and freshmeat, and routinely downloaded by hundreds or thousands of hackers (depending on the particular project). More than $90 \%$ of them will only use the software for their own work or hobbies. But most project leaders hope that a tiny percentage will do more than this, and turn into contributors. Then a cycle may ensue of ever improving public software. Only in this way, of course, popular programs such as Linux, Apache and Mozilla/Firefox could develop into programs of such enormous size (italics in Table 2). During the two decades of open source software (first without, later with the Internet) several instruments of governance have been invented to steer the process of so many volunteers working together across the globe [cf. De Laat 2004]. For one thing, these are technical instruments such as mailing lists, discussion forums, bug-tracking systems, and the concurrent versioning system (CVS) that allows to keep track of contributions by many authors. For another, organizational tools are employed such as introducing a division of tasks and grading of access within a project (a common hierarchy reads: observer, developer, project owner).

This call for a more active commons has not been answered to very frequently outside the domain of software. Open Access efforts are just promoting wider access to resources, to be used by professionals within existing organizations. No alternative paradigm of production is intended. An exception to this rule is, of 
course, the Wikipedia project (Table 2). Also here, users are invited to turn into contributors, and they seem to do so indeed. In the process, many of the technical instruments from open source software are copied (like the CVS and 'talk pages'). As for a division of roles, initially everyone had immediate change access to articles. Nowadays, in order to meet criticisms of low quality and resolve 'edit wars', its organizers gradually take to the same tool of hierarchy as the open source movement. Sysops (or administrators) have been appointed, who have various powers to try and resolve conflict (deleting articles, (un)freezing pages, (un)blocking user IP addresses). Moreover, the introduction of an editorial board of experts is being discussed that would put an official stamp of approval upon entries ('stable' article versions). So on this platform also, some division of labour seems unescapable.

\section{Patent Commons}

In this last section I will discuss the spectrum that sometimes haunts the creation of knowledge: patenting. While it obviously does not apply to the humanities or art, in many fields of science and technology patenting has become a standard tool for protecting intellectual property. In some fields the danger is, that patents do no longer seem to promote creativity but stifle it. The main instrument to curb the danger is the creation of pools to which participants contribute their patents in a specific field and license them to each other (or to a third party). Usually patent pools require grant back licenses for improvements of essential patents, in order to reduce the risk of future lawsuits among participants. Let me discuss the cases of software and biotechnology in turn.

As for software, since the early 1990 s software-related inventions may apply for a patent. It is estimated that currently, at least in the US, about 20,000 such patents are granted every year. As a result, anyone starting to compose source code is best advised to first perform a patent search and subsequently clear all the necessary rights. Without a search one risks to infringe many patents, and be surprised later on by royalty claims from patent holders. For software developers in bigger organizations this has become a fact of life. All other developers, however, lacking money and search facilities, are perpetually under threat of patents submerging and ruining their efforts.

In particular, this problem has existed for open source software for the last ten years now. Time and again, it is being discussed in those circles how to avert the danger. A tactic under consideration is to let hackers apply for patents themselves, and in the process compose a portfolio of patents that can be used for cross-licensing purposes if need be (just as big firms are used to). This tactic did as yet not materialize, simply because the movement is too loosely structured. Another more unexpected approach is materializing, though. Big firms like IBM, HP, and Intel, united in the Open Source Development Labs (OSDL), have been supporting the growth and adoption of Linux for several years now. In August 2005 they announced their 'patent commons project': a central location where patent licenses and patent 
pledges are to be deposited in support of the open source movement (Table 3; all information below retrieved from http://www.patentcommons.org).

Table 3. Various open patent initiatives classified according to the domain to which they apply

\begin{tabular}{ll}
\hline Domain $\downarrow$ & OSDL patent commons \\
\hline Software & BiOS protected commons \\
Biotechnology & .per prodion' \\
\hline
\end{tabular}

Italicized: initiative involved in 'peer production'.

As yet, patents have only been pledged, not licensed. The biggest contributor by far is IBM that committed not to assert 500 named patents against the development, use, or distribution of open source software generally (defined as any software carrying an 'official' open source license). Other firms have contributed much less patents and in a more restricted fashion. RedHat, e.g., will only pledge patents for open source software with a GPL, and Ericsson and Nokia will only pledge some patents for use in the (GPL-ed) Linux kernel specifically. Note that a patent license and a patent pledge differ in a subtle way: in the former case use is legally allowed, while in the latter case users continue to infringe but the patent holder promises not to sue.

As for biotechnology, patenting has been a fact of life much longer. There are some concerns, however, that patents may go too far as far as enabling technologies and genomic data (like sequences of DNA) are involved. Multiple patents that overlap, as well as patents stacking on top of each other may block the very development of science. Fears are that an 'anticommons' may materialize, of multiple owners holding rights of exclusion in a scarce resource [cf. Heller 1998]. Rapid release of genomic data into the public domain (a day or a week after production, but well before any possible analysis by the producers involved) is one type of defense, but increasingly companies seem to be able to develop follow up products that can be patented, effectively precluding use of the underlying public domain data. In response to this pressure, patent pools are being formed. Two initiatives deserve mentioning here.

First, the Canberra based initiative 'Biological Innovation for Open Society' (BiOS) focuses upon biotechnology (information below retrieved from http://www.bios.net/daisy/bios/home.html). According to them, patent portfolios of enabling technologies are to be opened up in a 'protected commons'. Anyone may obtain a royalty-free patent license of pool patents (a 'CAMBIA BiOS license'), on condition that further improvements are shared back to the pool. Patenting is explicitly allowed to go on: licensees may patent both improvements of the enabling technology itself and products based on them. The former kind of patents, however, is not to be asserted against pool members, so effectively being deposited inside the protected pool (not as license but as 'pledge', cf. above). As of today, BiOS has 
contributed 4 patents to the pool (Table 3). Its originators hope that the Bioforge platform (http://www.bioforge.net/forge/index.jspa) will become a meeting place in cyberspace where collaborative efforts are carried out, similar to sourceforge in open source software. So a community of biotech researchers involved in 'peer production' is the ultimate aim (italics in Table 3).

Secondly, the HapMap initiative deserves mentioning here (information retrieved from http://hapmap.org). This research effort involving institutions from several countries started in 2001 in order to produce a catalog of common genetic variations in human beings across the world. Such a 'HapMap' is useful information for further research linking genetic variants to specific diseases. For this purpose, DNA samples have been collected from populations all over the world. At the end of the project (December 2004), all results have been released in the public domain (Table 2). In the period before this, however, special precautions against appropriation were deemed necessary. The first results were provisionally released under a special copyright license [HapMap 2003]. The main provision was that licensees were not allowed to file patent applications on any so-called 'haplotype' information obtained from the pool, nor on particular uses of such information. Users were to be prevented from being faster than anyone else, incorporating pool data (together with their own data) in a patent application that met with success, and then starting to restrict access by others to the very same data.

What we find here, is a temporary commons, of the dynamic and protected variety (Table 2). And indeed, their copyright license is drafted along the lines of the GPL. Similarly, its wordings are comparable to the creative commons license 5: for all purposes, modifications allowed with the same license ('by-sa' license; cf. Table 1). In sum, here we find, instead of a patent pool proper, an unconventional approach to avert the danger of patenting: a (temporary) copyright-based commons of the protected kind.

\section{In Conclusion}

During the last two decades several kinds of commons for intellectual resources have opened up. The open source movement paved the way for this phenomenon, by creating a commons of source code, based on copyright and contract law. Two kinds of dynamic commons were introduced: one protected from commercial expropriation (regulated by the GPL) and an unprotected one (regulated by BSD-like licenses). Around the turn of the century this movement obtained a broader influence elsewhere: in the sciences, the humanities and art. It was the Creative Commons initiative that formulated a more comprehensive approach to copyright-based commons of text, essentially generalizing the open source typology and adding a static commons in which modification/derivation is not allowed (Table 1). Applications were discussed as implemented by the movement for Open Access in general, and PLOS and BioMed in particular (Table 2). The Wikipedia deserved special mention, as one of the few text-based commons run according to proper 'copyleft' principles. Thereupon, the epithet 'active' was coined for those commons 
that are not only destined to be a site for consumption but also for production of novel resources. This 'peer production of knowledge' does flourish in open source software communities, but rarely elsewhere. It was argued that in order to function properly, such active commons need instruments of self-governance, like a division of roles.

Finally, patent commons were distinguished. Examples discussed were the mutual pooling of patents on enabling biotechnologies in order to prevent blocking positions (BiOS), and the pooling of software patents on behalf of open source software developers while these lack the means to defend themselves against claims of patent infringement (OSDL pool). The HapMap initiative pioneered another approach to prevent patenting, by ingenuously instituting a copyright-based protected commons of genetic data. The analysis clearly indicated that copyrightbased commons and patent commons may be mutually related in various ways. This suggests strongly that, in the future, the various types of commons need to be studied as interrelated phenomena.

References (Websites mentioned in this article and in the references have all been accessed on 20 December 2005)

BSD, The BSD license (1998). Available at http://www.opensource.org/licenses/bsdlicense.php.

P.B. de Laat, Open source software: A case of swift trust?!, Challenges for the Citizen of the Information Society, Proceedings of the 7th International Conference, ETHICOMP 2004, edited by T.W. Bynum, N. Pouloudi, S. Rogerson, and Th. Spyrou (University of the Aegean, 2004), pp. 250-265.

P.B. de Laat, Copyright or copyleft? An analysis of property regimes in software development, Research Policy 34(10), 1511-1532 (2005).

FSF/GNU, GNU General public license, version 2 (1989/1991). Available at http://www.gnu.org/licenses/gpl.html.

FSF/GNU, GNU Free documentation license, version 1.2 (2002). Available at http://www.gnu.org/licenses/fdl.html.

HapMap, International HapMap Public Access License, version 1.1 (2003). Available at http://www.hapmap.org/cgi-perl/registration.

M.H. Heller, The tragedy of the anticommons: Property in the transition from Marx to markets, Harvard Law Review 111(3), 621-688 (1998).

L. Liang, Guide to open content licenses (Piet Zwart Institute, Rotterdam, 2004). Available: http://pzwart.wdka.hro.nl/mdr/pubsfolder/opencontentpdf.

OSI, The open source definition, version 1.9 (1997-2005). Available at http://www.opensource.org/docs/definition.php.

PLOS, Open-access publication of medical and scientific research: A PLOS background paper (2003). Available at http://www.plos.org/downloads/oa_background.pdf.

P. Suber, Open Access overview (2004/5). Available at http://www.earlham.edu/ peters/fos/overview.htm. 